\title{
PERANCANGAN DAN IMPLEMENTASI KEAMANAN PINTU BERBASIS PENGENALAN WAJAH DENGAN METODE EIGENFACE
}

\author{
Derian Indra Bramantio ${ }^{1}$, Erwin Susanto ${ }^{2}$, Ramdhan Nugraha ${ }^{3}$ \\ 1,2, ${ }^{3}$ Fakultas Teknik Elektro, Universitas Telkom \\ 1'derianib@student.telkomuniversity.ac.id, 2erwinelektro@telkomuniversity.ac.id, \\ ${ }^{3}$ ramdhan@telkomuniversity.ac.id
}

\begin{abstract}
Abstrak
Pengenalan wajah adalah hal yang mudah bagi manusia namun berbeda dengan pengenalan menggunakan mesin atau komputer. Kita mengidentifikasi orang dengan melihat mata dan wajah, begitu juga sama halnya dengan komputer. Pada penelitian ini pengenalan wajah akan diimplementasikan untuk membuka dan mengunci pintu secara otomatis. Aplikasi yang dibuat terdiri dari Raspberry Pi sebagai mini PC dengan bahasa pemrograman python. Sistem ini diharapkan bisa mencari sendiri posisi dari wajah di dalam sebuah citra. Algoritma yang digunakan adalah Eigenface atau yang biasa disebut dengan PCA ( Principle Component Analysis ). Penggunaan citra input diharapkan bisa menjadi lebih fleksibel, memiliki akurasi mencapai $90 \%$ sehingga hanya orang yang terdapat di database yang dapat masuk ke dalam rumah tersebut. Sedangkan motor servo dirancang agar dapat mengontrol posisi untuk membuka kunci.
\end{abstract}

Kata Kunci: Face Recognition, Pca, Eigenface, Raspberry Pi, Motor Servo

\section{Abstract}

Face recognition is easy for humans, different if face recognition use machine or computer. We identify by looking at their eyes and faces. So also the same as with a computer. Human is capable for identifying people more quickly and accurately. This face recognition will be implemented on the door via a servo motor. Implemented in the house because inside the house there are valuable items to protect. In order to make those items safe, the owner must add security system that only owner and their families can get into the house. This face recognition method created with python programming language by using Raspberry $\mathrm{Pi}$. Design of this system in order to seek its own position of a face in an image. The algorithm is Eigenface or commonly called PCA (Principle Component Analysis). The Expectation of this face recognition has to form the image more flexible and has an accuracy of up to $90 \%$ so that only people who are in a database that can be entered into the house. While the servo motor is designed in order to control the position to open the key slot.

\section{Keywords: Face Recognition, Pca, Eigenface, Raspberry Pi, Motor Servo}

\section{Pendahuluan}

Pada saat ini banyak pencuri yang berhasil memasuki rumah yang kosong tanpa menggunakan keamanan yang canggih. Biasanya menggunakan gembok pagar atau rantai. Oleh karena itu, penulis ingin membuat sistem keamanan yang canggih dan mengimplementasikan pada pintu.

Salah Satu sistem keamanan yang banyak digunakan pada saat ini adalah fingerprint dan password alarm. Sudah banyak alat-alat fingerprint yang sudah dijual di toko. Harganya pun termasuk masih mahal. Fingerprint itu mudah digunakan, akan tetapi mempunyai kelemahan yaitu jika orang tersebut luka pada sidik jarinya dan jika pencuri tersebut memiliki sidik jari pemilik rumah. Sidik jari dapat ditemukan misalnya jika pemilik rumah tersebut minum dari minuman kaleng lalu dibuang ke tempat sampah, dari minuman kaleng tersebut pasti terdapat sidik jari dari pemilik rumah dan akhirnya pencuri mendapat sidik jari pemilik rumah. Sedangkan untuk password alarm mempunyai kelemahan jika password itu tidak pernah diganti oleh pemiliknya sehingga terdapat bekas tombol-tombol yang pernah ditekan oleh pemiliknya

Oleh karena itu, penulis membuat face recognition untuk keamanan pintu. Sampai saat ini teknologi face recognition belum sempurna sehingga harus disempurnakan. Metode yang digunakan adalah PCA (Principle Component Analysis) atau biasa disebut dengan Eigenface. Sistem face recognition ini sangatlah unik karena muka manusia berbeda-beda. Contoh variabelnya seperti mata, hidung, dan mulut. Jadi metode ini pada dasarnya adalah mereduksi citra menjadi vektor ciri. Sehingga komputasi yang dilakukan akan menjadi lebih sedikit [1]. Simulasi 
pengambilan gambar wajah akan dilakukan beberapa kali hingga mendapatkan hasil yang terbaik [2].

Tujuan dari perancangan dan implementasi ini berdasarkan latar belakang yang telah dipaparkan sebelumnya, yaitu Membuat program untuk merancang sistem face recognition, merancang, dan mengimplementasikan face recognition yang akan di pasang pada pintu, dapat mengontrol posisi motor servo agar dapat membuka pintu dan dapat melaksukan analisis tingkat akurasi dari face recognition tersebut.

Rumusan masalah pada penelitian ini yaitu bagaimana cara merancang sistem face recognition agar tingkat akurasinya tinggi, cara merancang face recognition pada Raspberry Pi dan sistem kontrol posisi pada motor servo.

Pada penelitian ini terdapat dua metode yang akan digunakan, yaitu untuk mendeteksi muka dan pengenalan wajah. Untuk medeteksi muka akan digunakan metode Haar Like Feature, sedangkan untuk pengenalan wajahnya akan dilakukan metode Eigenface.

\section{Dasar Teori dan Perancangan}

\subsection{Haar Like Feature}

Haar Like Feature [3] yang memproses citra dalam wilayah kotak-kotak, berisi beberapa pixel dari bagian citra. banyak pixel dalam satu wilayah tersebut dijumlahkan dan dilakukan proses perhitungan (pengurangan rata-rata nilai pixel di bagian kotak yang terang dan gelap) sehingga diperoleh perbedaan nilai unik setiap wilayah kotakkotak tersebut.

\section{Edge features
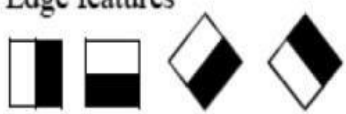 \\ (a) (b) \\ (c) (d)}

2. Line features
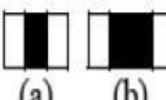

(b)

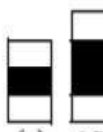

(c) (d)

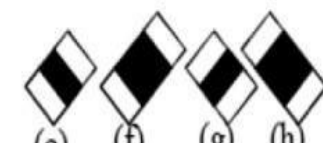

(e) (f) (g) (h)

3. Center-surround features

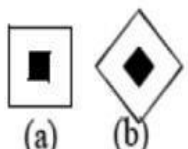

4. Special diagonal line feature

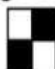

Gambar 1. Menunjukkan model fitur Haar Like yang dikembangkan oleh Lienhart, Kuranove dan Pisarevsky untuk mendeteksi objek wajah [4]

\subsection{Eigenface}

Metode Eigenface ditemukan oleh Matthew A Turk dan Alex P. Pentland dari MIT pada tahun 1991 [5]. Tujuan utama dari metode Eigenface adalah untuk mendapatkan karakteristik citra dengan tidak menggunakan karakteristik wajah tetapi dengan menggunakan rumus transformasi matematika.

\subsubsection{Tahap perhitungan Eigenface}

Menyiapkan database dengan membuat suatu himpunan $X$ yang terdiri dari seluruh training image. [5]

$$
X=\left[x_{1}, x_{2},,,, x_{n}\right]
$$

Mencari nilai mean gambar $(\mu)$

$$
\mu=\frac{1}{n} \sum_{i=n}^{n} x_{i}
$$

Menghitung matriks covarians ( S ). Dimana $\left(x_{i}-\mu\right)$ adalah selisih antara training image dengan mean dari wajah.

$$
s=\frac{1}{n} \sum_{i=1}^{n}\left(x_{i}-\mu\right)\left(x_{i}-\mu\right)^{T}
$$

Menghitung eigenvalues $\left(\lambda_{\mathbb{I}}\right)$ dan eigenvektor $v_{i}$ dari $\mathrm{S}$

$$
S v_{i}=\lambda_{i} v_{i}
$$

Mengurutkan eigen vektor secara menurun dengan eigenvalue. $K$ principal components adalah eigen vektor yang sesuai dengan eigenvalue nilai $\mathrm{k}$ terbesar. Memproyeksikan semua sampel pelatihan ke sub ruang PCA.

$$
y=W T(x-\mu)
$$

Dimana $W=(v 1, v 2, \ldots, v k)$. Memproyeksikan citra uji ke dalam subruang PCA

$$
x=W y+\mu
$$

Menemukan nilai terdekat antara gambar pelatihan yang diproyeksikan dan gambar uji yang diproyeksikan.

\subsection{Vektor}

Melalui persamaan (4), vektor akan digunakan karena jika menggunakan matriks perhitungannya akan sangat besar dan lambat. Menggunakan vektor menyebabkan ukuran gambar relatif lebih kecil jika dibandingkan dengan mengunakan bitmap. Dengan menggunakan vektor, perhitungan akan sangat 
berkurang dari urutan jumlah pixel dalam gambar dengan urutan jumlah gambar dalam training set. Dalam prakteknya, training set gambar wajah akan relatif kecil dan perhitungan menjadi sangat mudah dikelola.

\subsection{Cara kerja Sistem}

Gambar 2 dan Gambar 3 adalah diagram blok dan diagram alir dari sistem pengenalan wajah yang akan dibuat. Untuk Gambar 2, gambar diagram blok disini memiliki dua tahap pengambilan dan tahap pengenalan. Di tahap pengambilan ini foto yang diambil akan dijadikan database lalu akan disimpan hasilnya. Setiap foto berukuran $(250 \times 250)$ pixel. Lalu ada pre-processing. Dalam pre-processing itu sendiri ada empat tahap antara lain cropping, resize, grayscale, dan histogram equalization. Setelah melalui proses itu lalu foto akan melalui tahap Eigenface yang perhitungannya sudah dibahas sebelum ini. Lalu menuju tahap pengenalan, kedua matriks dari foto dibandingkan.Threshold adalah batas tingkat kemiripan. Dalam kasus ini kita menentukan threshold berdasarkan percobaan yang sudah dilakukan sebelumnya. Jika foto tersebut melampaui batas threshold yang ditentukan sebelumnya maka foto tidak akan dikenali.

\subsection{Implementasi}

Alat akan diimplementasikan pada motor servo. Pertama-tama ketika orang ingin membuka pintu. Orang tersebut harus menghadap webcam agar foto dari wajahnya bisa diambil. Setelah itu sistem akan mulai bekerja untuk mulai mengolah foto itu lalu dikalkulasikan dengan menggunakan algoritma Eigenface. Setelah itu akan muncul tulisan bawah foto itu dapat atau tidak dikenali. Jika dapat dikenali maka sistem akan mengirim sinyal berupa pulse yang akan diterima oleh motor servo dan akhirnya motor servo akan berputar untuk membuka pintu. Setelah 10 detik, kunci akan otomatis terkunci kembali.

\section{Pengujian dan Pembahasan}

Pengujian yang dilakukan bertujuan untuk menguji seberapa besar sistem layak untuk digunakan. Pengujian dilakukan dengan menguji kesamaan antara gambar yang sudah disimpan di database dengan gambar yang mirip dengan yang tersimpan di database. Pada Tabel 1(a) dan Tabel 1(b) adalah tabel hasil pengujian. Tabel 1(a) adalah pengujian terhadap foto yang sama dari database yang disediakan.

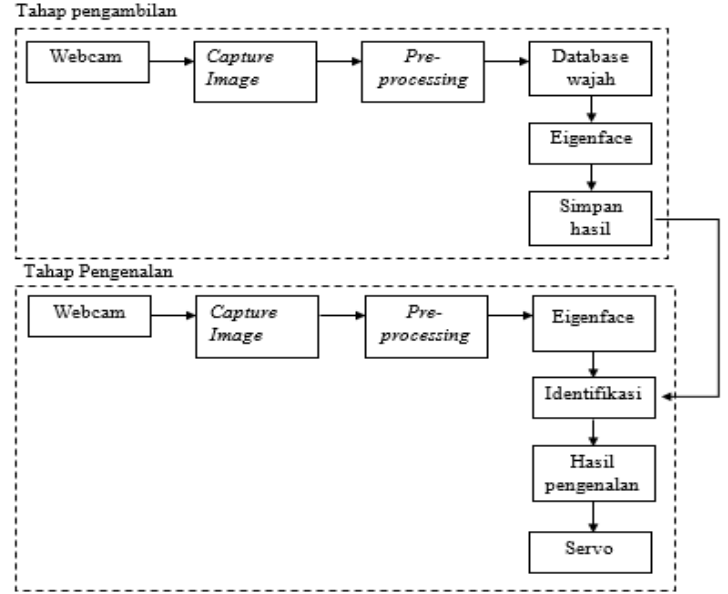

Gambar 2. Diagram blok system

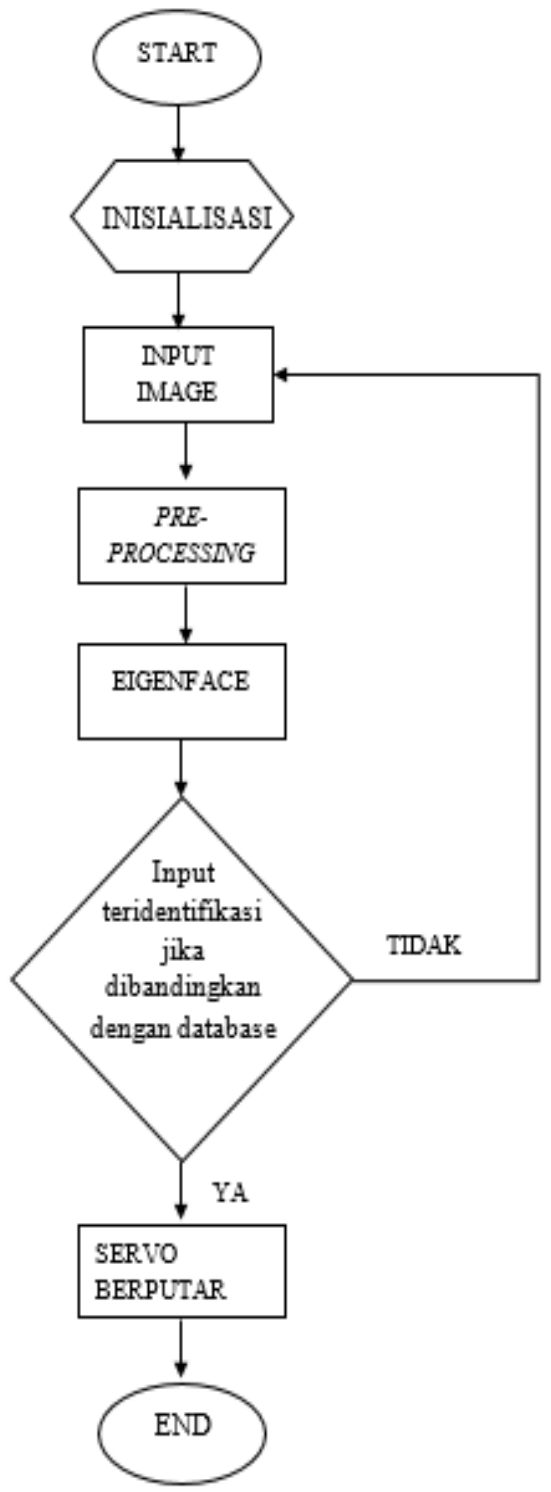

Gambar 3. Diagram alir dari sistem 
Tabel 1(a). pengujian pada gambar yang sama

\begin{tabular}{|c|l|r|}
\hline No & Gambar yang di uji & Hasil Predict \\
\hline 1 & Database I - Gambar 1 & 0,0 \\
\hline 2 & Database I - Gambar 2 & 2572,35 \\
\hline 3 & Database I - Gambar 3 & 3155,36 \\
\hline 4 & Database I - Gambar 4 & 3651,69 \\
\hline 5 & Database I - Gambar 5 & 4508,42 \\
\hline 6 & Database II - Gambar 1 & 0,0 \\
\hline 7 & Database II - Gambar 2 & 4168,79 \\
\hline 8 & Database II - Gambar 3 & 5808,67 \\
\hline 9 & Database II - Gambar 4 & 4925,29 \\
\hline 10 & Database II - Gambar 5 & 3573,61 \\
\hline 11 & Database III - Gambar 1 & 0,0 \\
\hline 12 & Database III - Gambar 2 & 3031,55 \\
\hline 13 & Database III - Gambar 3 & 2147,16 \\
\hline 14 & Database III - Gambar 4 & 3491,81 \\
\hline 15 & Database III - Gambar 5 & 3232,12 \\
\hline 16 & Database IV - Gambar 1 & 0,0 \\
\hline 17 & Database IV - Gambar 2 & 4627,72 \\
\hline 18 & Database IV - Gambar 3 & 3315,73 \\
\hline 19 & Database IV - Gambar 4 & 1449,35 \\
\hline 20 & Database IV - Gambar 5 & 3056,15 \\
\hline
\end{tabular}

Tabel 1(b). pengujian pada gambar yang mirip

\begin{tabular}{|c|l|r|}
\hline No & \multicolumn{1}{|c|}{ Gambar yang di uji } & $\begin{array}{c}\text { Hasil } \\
\text { Predict }\end{array}$ \\
\hline 1 & Database I - Gambar 1 & 4737,38 \\
\hline 2 & Database I - Gambar 2 & 6351,70 \\
\hline 3 & Database I - Gambar 3 & 5873,87 \\
\hline 4 & Database I - Gambar 4 & 3334,53 \\
\hline 5 & Database I - Gambar 5 & 4428,39 \\
\hline 6 & Database II - Gambar 1 & 4469,16 \\
\hline 7 & Database II - Gambar 2 & 5189,13 \\
\hline 8 & Database II - Gambar 3 & 4875,85 \\
\hline 9 & Database II - Gambar 4 & 6771,11 \\
\hline 10 & Database II - Gambar 5 & 3435,05 \\
\hline 11 & Database III - Gambar 1 & 5541,30 \\
\hline 12 & Database III - Gambar 2 & 3301,48 \\
\hline 13 & Database III - Gambar 3 & 3524,34 \\
\hline 14 & Database III - Gambar 4 & 2694,16 \\
\hline 15 & Database III - Gambar 5 & 4899,71 \\
\hline 16 & Database IV - Gambar 1 & 3531,90 \\
\hline 17 & Database IV - Gambar 2 & 4359,15 \\
\hline 18 & Database IV - Gambar 3 & 4822,65 \\
\hline 19 & Database IV - Gambar 4 & 4094,43 \\
\hline 20 & Database IV - Gambar 5 & 4219,37 \\
\hline
\end{tabular}

Tabel 1(b) adalah pengujian terhadap foto yang mirip, artinya foto ini diambil langsung melalui webcam hanya dengan pencahayaan yang sama karena cahaya salah satu faktor penting untuk menambah akurasi. Hasil angka ini yang nanti akan dipergunakan untuk threshold. Angka predict ini didapatkan dari hasil prehitungan algoritma Eigenface.

\subsection{Penentuan threshold}

Hasil dari pengujian terhadap gambar yang sama predict berada di angka maksimal. Sedangkan pengujian terhadap gambar yang mirip berada di angka maksimal. Pengujian terhadap gambar yang berbeda predict-nya di angka. Setelah mendapatkan hasil predict dari kedua tabel 1(a) dan 1(b) diatas maka dapat disimpulkan untuk threshold-nya harus dengan kriteria persis diatas angka predict terhadap gambar yang sama dan gambar yang mirip. Jadi dapat diambil kesimpulan, threshold yang akan digunakan di angka 6000.

\subsection{Tingkat akurasi}

Dalam pengenalan wajah, akurasi yang didapatkan sangatlah susah jika harus $100 \%$ karena banyak faktor-faktor yang dapat mengurangi akurasi. Contohnya seperti cahaya, tempat pengambilan foto atau mungkin bisa wajahnya. Jadi, akan dihitung seberapa besar akurasi yang didapatkan dari penelitian ini.

Akurasi ini akan dibagi dua. Pertama, akurasi jika pengujiannya menggunakan database yang ada. Kedua, jika pengujiannya langsung menggunakan webcam. Untuk akurasi yang didapatkan dari pengujian menggunakan database yang sudah ada diperoleh hasil sebagai berikut. Dari pengujian yang dilakukan sebanyak 50 kali. Wajah yang berhasil dikenal sebanyak 50 dan tidak dikenal 0. Oleh karena itu untuk akurasi pengujian terhadap database yang ada sebesar $100 \%$.

Dengan menggunakan threshold sebesar 6000,00 . Untuk akurasi yang kedua yaitu jika pengujianya melalui webcam dari 50 kali percobaan yang dilakukan didapatkan hasil sebagai berikut. Dari 50 kali dapat dikenali sebanyak 46 buah gambar sedangkan empat gambar sisanya tidak dapat dikenali. Sehingga didapatkan perhitungan akurasi sebesar $92 \%$.

\section{Kesimpulan}

Setelah melakukan perencanaan pemrograman perangkat lunak sistem pengenal wajah (face recognition) serta melalui pengujian dengan sudah menggunakan kunci. Sistem pengenalan wajah (face recognition) dengan menggunakan metode Eigenface dapat mengenali orang sesuai dengan label (nama) yang diberikan pada database dan 
tidak dapat mengenali orang yang tidak terdapat di database dan pada penelitian ini, dengan menggunakan database hasil dari foto yang dibuat sendiri ukuran tiap foto yang digunakan adalah (250x250) pixel dengan sudah hasil pre-processing maka diperoleh persentase akurasi sebesar $92 \%$ dari 50 kali percobaan.

Setelah berhasil dalam mengenali wajah, sistem mengirimkan sinyal berupa pulse kepada servo agar dapat berputar untuk membuka kunci.

\section{Daftar Pustaka}

[1] Sigit W, Bima SBD, Sandra AP, Sistem Pengenalan Wajah Pada Mesin Absensi Mahasiswa Menggunakan Metode PCA Dan DTW, Indonesia: Electronic Engineering Polytechnic Institute of Surabaya (EEPIS), 2011.

[2] Dewi AR., Indri Septadepi , Face Recognition System Using Eigenface Method based on Facial Component Region, Department of Informatics Gunadarma University, 2010.

[3] Freund Y. \& Schapire R, "A Short Introduction to Boosting," Journal of Japanese Sociaety for Artificial Intelegence, pp. 14(5)780, 1999.

[4] Lienhart, R \& Maydt, J, "An extended Set of Haar-like Features for Rapid Object Detection," IEEE ICIP 2002, pp. 900-903, 2002.

[5] Matthew A. Turk and Alex P. Pentland, Face Recognition Using Eigenfaces, IEEE, 1991, 2005. 